elephant trunk technique: unique protocol from one institution. Eur Rev Med Pharmacol Sci 2021 2514 4738-4745 DOI 1026355 eurrev20210726384.

4. 2014 ESC Guidelines on the diagnosis and treatment of aortic diseases: Document covering acute and chronic aortic diseases of the thoracic and abdominal aorta of the adultThe Task Force for the Diagnosis and Treatment of Aortic Diseases of the European Society of Cardiology (ESC). Eur Heart J. 2014;35(41):2873-2926. doi:10.1093/ eurheartj/ehu281

5. Ricotta Jj. Endoleak management and postoperative surveillance following endovascular repair of thoracic aortic aneurysms. J Vasc Surg.
2010;52(4):91S-99S.

doi:10.1016/j.jvs.2010.06.149

6. Ameli-Renani $S$, Pavlidis $V$, Morgan RA. Secondary Endoleak Management Following TEVAR and EVAR. Cardiovasc Intervent Radiol. 2020; 43(12):1839-1854. doi:10.1007/s00270-020-02572-9

7. Parmer SS, Carpenter JP, Stavropoulos SW, et al. Endoleaks after endovascular repair of thoracic aortic aneurysms. J Vasc Surg. 2006;44(3):447452. doi:10.1016/j.jvs.2006.05.041

8. Chen J, Stavropoulos SW. Management of Endoleaks. Semin Interv Radiol. 2015;32(3):259264. doi: $10.1055 / \mathrm{s}-0035-1556825$

\title{
KẾT QUẢ XẠ TRỊ 3D-CRT VÀ VMAT TRONG HOÁ XẠ ĐỒNG THỜI UNG THƯ THỰC QUẢN TẠI BỆNH VIỆN K
}

\author{
Nguyễn Thanh Tùng ${ }^{1}$, Võ Văn Xuân ${ }^{2}$
}

\section{TÓM TẮT}

Mục tiêu: Mô tả một số đặc điểm lâm sàng, cận lâm sàng và đánh giá kết quả xạ trị bằng kỹ thuật 3DCRT và VMAT ở bệnh nhân hoá xạ đồng thời ung thư thực quản tại bệnh viện $K$. Đối tượng và phương pháp nghiên cứu: Nghiên cứu mô tả hồi cứu kết hợp tiến cứu trên 60 bệnh nhân điều trị hoá xạ đồng thời ung thư thực quản bằng kỹ thuật 3D-CRT và VMAT tại bênh viên $K$ từ tháng $5 / 2018$ đến tháng $5 / 2021$. Kểt quả: Tuổi trung bình 54,4 $\pm 7,0$ (43-69). Tỷ lệ nam/nũ là 59/1. Tỷ lệ nuốt nghẹn $91,7 \%$. Có 46 (76,7\%) bệnh nhân giai đoạn T3, 14 (23,3\%) bệnh nhân ở giai đoạn T4. Thể giải phẫu bênh của các bệnh nhân là ung thư biểu mô vảy $(100 \%)$. Các thông số bao phủ liều đến PTV (thể tích xạ kế hoạch - Planning target volume) của xạ trị VMAT so với 3D-CRT: V95: $98,4 \%$ 94,35\%, V110: 0,15\% - 5,35\%. Dmax tại tuỷ và da VMAT thấp hơn so với 3D-CRT. Liều tại phổi $(\mathrm{V} 5, \mathrm{~V} 20)$ và tại tim (V40) VMAT thấp hơn so với 3D-CRT.Tỷ lệ đáp ứng toàn bộ sau hóa xa trị là $48,3 \%$, tỷ lệ đáp ứng 1 phân là $41,7 \%$, tỷ lệ bệnh không đổi là $10 \%$. Đốc tính trên hệ huyết học là hạ bach câu $(6 \%)$, hạ tiểu câu $(1,7 \%)$. Độc tính viêm da do xạ trị $(58,4 \%)$, viêm thực quản do xạ trị $(18,3 \%)$, độc tính viêm phổi do xạ trị $(3,3 \%)$, không ghi nhận độc tính trên hệ tim mạch. Kết luân: Xa trị ung thư thực quản bằng kỹ thuật VMAT và 3D-CRT cho kết quả tốt và an toàn, kỹ thuật VMAT cho thây tập trung liều xạ tốt hơn và ít độc tính hơn kỹ thuật 3D-CRT.

Tư khóa: ung thư thực quản, hóa xạ trị đồng thời, kỹ thuật 3D-CRT, kỹ thuật VMAT

\section{${ }^{1}$ Trường Đại học Y Hà Nội \\ ²Bênh viện $K$}

Chịu trách nhiệm chính: Nguyễn Thanh Tùng

Email: dr.tungnguyen710@gmail.com

Ngày nhận bài: 26.7.2021

Ngày phản biện khoa học: 27.9.2021

Ngày duyệt bài: 1.10.2021

\section{SUMMARY}

THE RESULTS OF 3D-CRT VS VMAT IN CONCURRENT CHEMORADIOTHERAPY FOR ESOPHAGEAL CANCER

Objective: Describe some clinical and paraclinical characteristics and evaluate the results of radiaotherapy by 3D-CRT and VMAT techniques in patients with concurrent chemoradiotherapy with esophageal cancer at K hospital. Subjects ad methods: A retrospective and prospective descriptive study on 60 patients undergoing concurrent chemoradiotherapy for esophageal cancer with 3DCRT and VMAT techniques at $\mathrm{K}$ hospital from May 2018 to May 2021. Results: Mean age $54.4 \pm 7.0$ (43-69). The male/female ratio is $59 / 1$. Swallowing rate $91.7 \%$. There are $46(76.7 \%)$ patients at T3 stage, $14(23.3 \%)$ patients at T4 stage. The histopathology of the patients was squamous cell carcinoma $(100 \%)$. Parameters of dose coverage to PTV (planning target volume) of VMAT radiotherapy compared with 3D-CRT: V95: $98.4 \%$ - 94.35\%, V110: $0.15 \%-5,35 \%$. Dmax at marrow and skin VMAT is lower than 3D-CRT. The dose in the lungs $(\mathrm{V} 5, \mathrm{~V} 20)$ and at the heart (V40) of VMAT was lower than that of 3D-CRT. The overall response rate after chemotherapy and radiotherapy was $48.3 \%$, the partial response rate was $41.7 \%$, the disease rate remained unchanged at $10 \%$. Hematologic toxicity was leukopenia (6\%), thrombocytopenia (1.7\%). Radiation-induced dermatitis $(58.4 \%)$ radiation-induced esophagitis $(18.3 \%)$, radiation-induced pneumonia toxicity (3.3\%), no cardiovascular toxicity was noted. Conclusion: Radiation therapy for esophageal cancer by VMAT and 3D-CRT techniques gives good and safe results, the VMAT technique shows better radiation dose concentration and less toxicity than 3D-CRT technique.

Keywords. Esophagus Cancer, concurrent chemoradiotherapy, 3D-CRT technique, VMAT technique.

\section{I. ĐĂT VẤN ĐỀ}

Theo GLOBOCAN 2018, ung thư thực quản 
(UTTQ) đứng thứ 7 trong các bệnh ác tính, phổ biến nhất trên thế giới và đứng thứ 3 trong các ung thư đường tiêu hóa sau ung thư đai trực tràng và da dày với 572034 ca mới mắc.ớ chẩu Á, tỷ lệ ung thư thực quản mới mắc là $5,1 \%$ tổng các ca bệnh mới mắc (1).

Tại Việt Nam, theo ghi nhận của Nguyễn Bá Đức và CS trong giai đoạn 2001-2003 tî lệ mắc ung thư thực quản tại Hà Nội ở nam là $8,7 / 100000$ dân và ở nữ là $1,7 / 100000$. Nghiên cứu của Nguyễn Đức Lợi tỷ lệ ung thư thực quản $1 / 3$ giữa là $58,3 \%$ và $1 / 3$ dưới là $17,4 \%$. Tỷ lệ giai đoạn T3 là 42.4\%,T4a là 34,8\%(2).

Về điều trị, phẫu thuật vẫn là điêu trị chuẩn cho ung thư thực quản ở giai đoạn sớm, tuy nhiên chỉ khoảng 30-40\% số bệnh nhân ở thời điểm chẩn đoán là có thể phẫu thuâat. Hóa xạ trị đồng thời là phương thức điều trị chính cho ung thư thực quản ở giai đoạn tiến triển tại chỗ hoặc không thể phẫu thuật. Tuy nhiên tỷ lệ sống thêm toàn bộ 5 năm chỉ khoảng $15-25 \%$. Thất bại kiểm soát bệnh tại chỗ thường gặp với hóa xạ trị đồng thời và tỷ lể tồn tại bệnh tại chỗ gặp ở 60$70 \%$ bệnh nhân. Thể tích xạ trị lớn liên quan tới tăng nguy cơ độc tính do tia xạ, độc tính mức độ 3 hoặc hơn được ghi nhận tới 15\% số bệnh nhân trong quá trình điêu trị và có thể làm chậm tiến trình điều trị. Vì vậy, lựa chọn kỹ thuật xă trị để giảm tối đa độc tính các cơ nguy cấp và vẩn đảm bảo đủ liều xạ các thể tích điều trị là rất quan trọng. Các kĩ thuật xạ trị được áp dụng trong điều trị ung thư thực quản gồm: kỹ thuật xạ 3D (3D-Conformal Radiotherapy-3DCRT), kỹ thuật xạ trị điều biến thể tích hình cung VMAT (Volumetric Modulated arc Radiotherapy), chưa có nghiên cứu nào đánh giá kết quả điều trị khi sử dụng các kỹ thuật trên và có sự đồng thuận rằng kỹ thuật nào sẽ̃ tối ưu hơn cho bệnh nhân. Chính vì vậy chúng tôi thực hiện nghiên cứu: "Kết quả xạ trị 3D-CRT và VMAT trong hoá xạ đồng thời ung thư thực quản tại Bệnh viện $K^{\prime \prime}$

\section{II. ĐỐI TƯƠNG VÀ PHƯƠNG PHÁP NGHIÊN CỨU}

2.1.Đối tượng nghiên cứu. $B N$ với chẩn đoán ung thư thực quản được điều trị hoá xạ đồng thời, xạ trị bằng kỹ thuật 3D-CRT hoặc VMAT giai đoan từ T5/2018-T5/2021

\section{Tiêu chuẩn lựa chon bênh nhân}

- Các BN ung thư thực quản giai đoạn T34,N0-2, M0 theo phân loại của Hiệp hội chống ung thư quốc tế 2017 (UICC 2017). UT biểu mô vảy

- Vị trí ung thư thực quản ở 1/3 giữa, 1/3 dưới.

- Ung thư thực quản 1 vị trí.

- Các BN được điều trị lần đầu.
- BN có chỉ định hoá xạ trị đồng thời

- Thể trạng chung: Chỉ số toàn trạng từ 0-2 theo thang điểm ECOG

- Chức năng tuỷ xương, gan, thận không chống chỉ định điều trị hoá chất kết hợp.

\section{Tiêu chuấn loai trừ}

- Bênh nhân ung thư thực quản $1 / 3$ trên.

- Bệnh nhẫn đã phẫu thuật trước đó

- Ung thư thực quản tái phát hoặcmắc ung thư thứ hai

- Bệnh nhân có nguy cơ tử vong gần do các bệnh trầm trọng khác.

- BN bỏ dở điêu trị.

\subsection{Phương pháp nghiên cứu}

Thời gian nghiên cứu: Từ tháng 05/2018 đến tháng 05/2021.

Địa điểm nghiên cứu: Bệnh viện $\mathrm{K}$

Thiết kế nghiên cứu: Phương pháp nghiên cứu mô tả hồi cứu kết hợp tiến cứu.

\section{Cỡ mẫu}

- Chọn mẫu thuận tiện.

- Chọn các bệnh nhân đủ tiêu chuẩn trong thời gian nghiên cứu.

- Trong nghiên cứu chúng tôi chọn cõ mẫu tối thiểu là 60 bệnh nhân.

\section{KẾT QUẢ NGHIÊN CỨU}

\section{1. Đặc điểm lâm sàng và cận lâm sàng} của nhóm bệnh nhân nghiên cứu.

- Tuổi

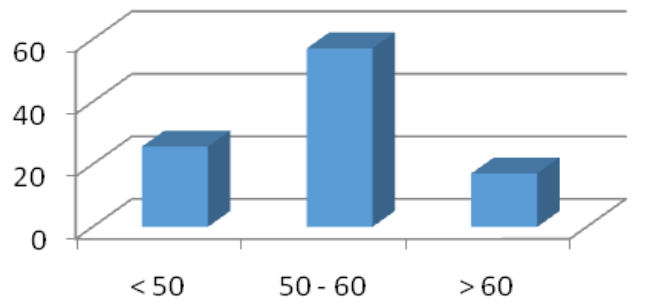

Nhận xét: Tuổi trung bình là 54,4. Cao tuổi nhất là 69, thấp nhất là 43 tuổi

- Giới

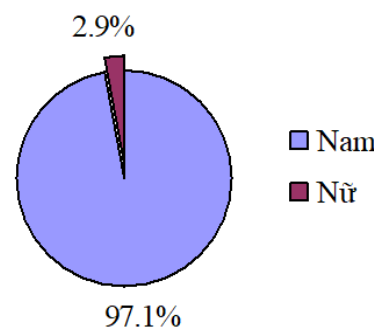

Nhận xét: Tỷ lệ nam/nữ là 59/1 trong đó nam chiếm $98,3 \%$

- Lý do vào viện 


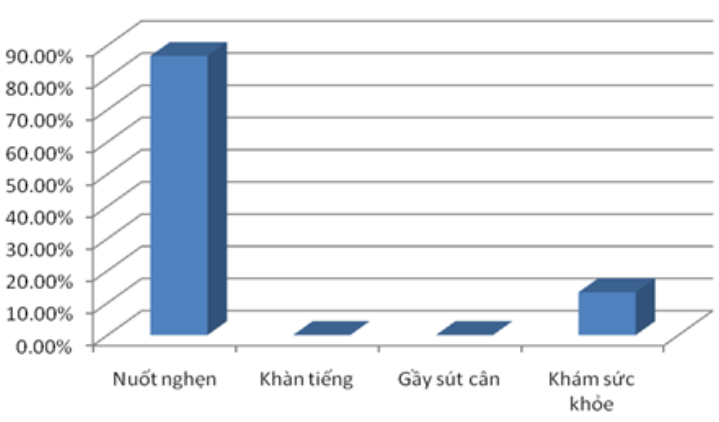

Nhânn xét: Lý do vào viện chủ yếu là nuốt nghen chiếm 91,7\%.

Mức độ xâm lấn của u

Bảng 1. Mức độ xâm lấn của u trước điều tri

\begin{tabular}{|c|c|c|}
\hline Tình trạng u & Số BN & \% \\
\hline T3 & 46 & 76,7 \\
\hline T4 & 14 & 23,3 \\
\hline
\end{tabular}

Nhân xét: Trong nghiên cứu của chúng tôi số bệnh nhân ở giai đoạn T3 chiếm $76,7 \%$, giai đoạn T4 là 23,3\%

- Kết quả lập kế hoạch xạ trị 3D-CRT và VMAT:

Bảng 3: Giá trị trung binh chi định phân bố tới PTV

\begin{tabular}{|c|c|c|c|}
\hline \multicolumn{2}{|c|}{ PTV } & 3D-CRT & VMAT \\
\hline \multirow{2}{*}{ Dmax(Gy) } & Body & 58.47 & 55.32 \\
\cline { 2 - 4 } & Tủy & 43.25 & 39.45 \\
\hline \multirow{2}{*}{ V5(Gy) } & Phổi trái & 81.25 & 78.80 \\
\cline { 2 - 4 } & Phối phải & 74.12 & 68.50 \\
\hline \multirow{2}{*}{ V20(Gy) } & Phổi trái & 35.56 & 34.24 \\
\cline { 2 - 4 } & Phối phải & 29.78 & 25.15 \\
\hline \multirow{2}{*}{ V40(GY) } & Tổng phổi & 32.54 & 29.81 \\
\cline { 2 - 4 } & Tim & 29.85 & 22.45 \\
\hline V95(\%) & & 94.35 & 98,4 \\
\hline V110(\%) & & 5.35 & 0.15 \\
\hline
\end{tabular}

Nhân xét: Phân bố liều tới PTV của kỹ thuâtt VMAT cho kết quả tốt hơn 3D-CRT. V95\% kỹ thuât VMAT đat 98,4 so với 94,35 của kĩ thuật 3D-CRT. Phổi chịu liêu 25,15 so với 29,78.

\subsection{Kết quả điều tri.}

3.2.1.Kêt quá đîêu tri sau hóa xa đôông thời Bảng 4: Đánh giá đáp ứng sau hóa xạ đồng thời

\begin{tabular}{|c|c|c|}
\hline Đáp ứng & Số $\mathbf{B N}$ & $\mathbf{\%}$ \\
\hline Đáp ứng hoàn toàn & 29 & 48,3 \\
\hline Đáp ứng bán phần & 25 & 41,7 \\
\hline Không đáp ứng & 6 & 10 \\
\hline
\end{tabular}

Nhânn xét: Tỉ lệ đáp ứng hòa toàn là 29 bệnh nhân, chiếm 48,3\%. đáp ứng một phân là 25 bệnh nhân chiếm $41,7 \%$, có 6 bệnh giữ nguyên.

\subsubsection{Các tác dụng phy:}

\section{Bảng 5: Độc tính trên hệ huyêt học}

\begin{tabular}{|c|c|c|c|}
\hline Hệ tạo máu & Độ độc tính & Số BN & \% \\
\hline Hồng câu & 0 & 60 & 100 \\
\hline \multirow{2}{*}{ Bạch câu } & 0 & 54 & 90 \\
\cline { 2 - 4 } & 1 & 6 & 10 \\
\hline \multirow{2}{*}{ Tiểu câu } & 0 & 59 & 98,3 \\
\cline { 2 - 4 } & 1 & 1 & 1,7 \\
\cline { 2 - 4 } & 2 & 0 & 0 \\
\hline
\end{tabular}

Nhân xét; Độc tính về huyết họchạ bạch câu độ $10 \%$ và $1,7 \%$ bệnh nhân hạ tiểu câu độ 1

Bảng 6: Tác dụng phy của xạ trị

\begin{tabular}{|c|c|c|c|}
\hline Cơ quan & Biến chứng & Số $\mathbf{B N}$ & $\mathbf{\%}$ \\
\hline \multirow{2}{*}{ Da } & Độ 0 & 32 & 58,3 \\
\cline { 2 - 4 } & Độ 1 & 28 & 41,7 \\
\hline \multirow{2}{*}{$\begin{array}{c}\text { Thực } \\
\text { quản }\end{array}$} & Không viêm TQ & 49 & 81,7 \\
\cline { 2 - 4 } & Độ 1 & 11 & 18,3 \\
\hline \multirow{2}{*}{ Phổi } & Có & 58 & 96,7 \\
\cline { 2 - 4 } & Không viêm phối & 2 & 3,3 \\
\hline \multirow{2}{*}{ Tim mạch } & Có & 0 & 0 \\
\cline { 2 - 4 } & Không & 60 & 100 \\
\hline
\end{tabular}

Nhân xét: Viêm da độ 1 là 41,7\% trong đó 15 bệnh nhân xa trị bằng kĩ thuât 3D-CRT, $13 \mathrm{BN}$ xạ trị bằng kĩ thuật VMAT. Chỉ có $11(17,1 \%)$ bệnh nhân viêm thực quản đô 1 , trong đó 7 BN xạ bằng kĩ thuật 3D-CRT, 4 BN xạ bằng kĩ thuật VMAT.

\section{BÀN LUÂN}

4.1. Một số đặc điểm lâm sàng, cận lâm sàng. Tuổi mắc bệnh trong nghiên cứu của chúng tôi nằm trong khoảng từ 43 - 69 tuổi. Tuổi mắc bệnh trung bình là 54,4 tuổi. Theo kết quả này thì tuổi trung bình của bệnh nhân trong nghiên cứu của chúng tôi thấp hơn so với các tác giả khác như Shapiro và cs tuổi trung bình của bệnh nhân trong nghiên cứu là $60^{5}$, theo Stahl tuổi trung bình của bệnh nhân là 57 tuổi 6 .

Trong nghiên cứu của chúng tôi bệnh gặp chủ yếu ở nam giới, chiếm tỷ lệ 98,3\%, tỷ lệ nam/ nữ là 59/1. Kết quả này cũng tương tự với kết quả của tác giả Nguyễn Đức Lợi là 98,5\%7. Tỷ lệ này tương tự với nghiên cứu của Tepper với tỷ lệ nam là $93 \%$, tỷ lệ nam/ nữ là $28 / 2^{8}$

* Lý do vào viến. Trong nghiên cứu của chúng tôi, tỷ lệ bệnh nhân vào viện vì triệu chứng nuốt nghẹn là 91,7\%, kêt quả này tương tự với nghiên cứu của tác giả Nguyễn Đức Lợi là $87,9 \% 7$. Các triệu chứng khác như đau tức ngực và khan tiếng hâu như không gặp, có 5 bệnh nhân không có triệu chứng gì mà tình cờ phát hiện khối u khi kiểm tra sức khoẻ định kỳ. Điêuu này có thể do đa số bệnh nhân trong nghiên cứu của chúng tôi đều được phát hiện sớm nên chưa có các triệu chứng chèn ép, cũng như các triệu chứng toàn thân rầm rộ. 
*Giai đoạn bệnh: Trong nghiên cứu của chúng tôi chỉ lấy những bệnh nhân ung thư thực quản ở giai đoạn T3 đến T4. Trong đó tỷ lệ bệnh nhân ở giai đoạn T3 cao hơn gấp ba lần so với giai đoạn T4 ở mức $76,7 / 23,3$. Tỷ lệ này cao hơn so với nghiên cứu của Nguyễn Đức Lợilà 48,5/ 51, $5^{7}$.

4.2. Kết quả điêu trị. Kết quả điều trị sau hóa xạ đồng thời: Trong nghiên cứu của chúng tôi, sau hóa xạ trị đồng thời số lượng bệnh nhân đánh giá đáp ứng hoàntoàn là 29 bệnh nhân, chiếm 48,3\%. Số bệnh nhân đáp ứng bán phần là 25 bênh nhân chiếm $41,7 \%$, có 6 bênh nhân không thay đổi so với trước điều trị. Kết quả nghiên cứu của chúng tôi cũng tương tự với kết quả nghiên cứu của tác giả Fednandino De Vita với 39 bệnh nhân hóa xạ đồng thời tiền phẫu có tỷ lệ đáp ứng hoàn toàn, đáp ứng 1 phần, và bệnh không đổi là 33,3\%; 48,7\%; 18\% sau hóa xạ tiền phẫu'.

Kết quả lập kế hoach xa trị 3D-CRT và VMAT: Trong nghiên cứu của chúng tôi, kỹ thuật VMAT cho kết quả vượt trội so với kỹ thuật 3D-CRT về các thông số giá trị trung bình phân bố tới PTV. Liều bao phủ 95\% PTV (V95) đạt 98,4\% ở kỹ thuật VMAT so với 94,35\% ở kỹ thuật 3D-CRT, quá liều $110 \%$ cũng thấp hơn nhiều

\subsection{Tác dụng phụ}

\section{- Độc tính trên huyết học, gan, thâan}

Trong quá trình điều trị đến khi kết thúc hóa xạ trị đồng thời, ít gặp tác dụng phụ $\geq$ độ 2 ở cả trên huyết học và ngoài huyết học, chỉ có 6 trường hợp bị hạ bạch cầu cũng như bạch cầu trung tính độ 1 (chiếm 10\%bệnh nhân). Có một bệnh nhân hạ tiểu cầu độ 1 với tỷ lệ là 1,7\%.

- Tác dụng phụ của xạ trị

Viêm thực quản do tia xạ: tỷ lệ bệnh nhân bị viêm thực quản trong quá trình điều trị là 18,3\%, trong đó tất cả bệnh nhân là độ 1, không có bệnh nhân viêm độ 2 trở lên. Kết quả này thấp hơn với nghiên cứu của Hàn Thị Thanh Bình, tỷ lệ viêm thực quản là $37,2 \%$, trong đó độ 1 là $19,8 \%$, độ 2 là $9,9 \%{ }^{3}$. Theo nghiên cứu của Tepper và cộng sự, tỷ lệ viêm thực quản là $42 \%^{8}$.

Trên da: các tổn thương da do tia xạăgạp tỷ lệ 41,7\% bệnh nhân, tất cả là bỏng da độ 1 với biểu hiện đỏ da và xạm da vùng xạ. Kết quả này cao hơn so với nghiên cứu của Hàn Thị Thanh Bình là $10,7 \%^{3}$ của Nguyễn Đức Lợi là $88,2 \%{ }^{7}$

Tại phổi: 2 bệnh nhân viêm phổi độ 1 chiếm $3,3 \%$ trong đó 2 bệnh nhân này đều xạ trị bằng kỹ thuật 3D-CRT, cho thấy kỹ thuật VMAT với liêu xạ phổi phải nhận thấp hơn so với kỹ thuật 3D-CRT có thể làm giảm tỷ lệ $\mathrm{BN}$ mắc tác dụng phụ viêm phổi do xạ trị, tuy nhiên do thời gian theo dõi chưa dài, cỡ mẫu còn tương đối nhỏ nên đây là nhận định sơ bộ bước đầu, cần tiến hành nhiều nghiên cứu với số mẫu lớn và thời gian dài hơn để có thể khẳng định.

Trên hệ tim mạch: Nghiên cứu của chúng tôi chưa ghi nhận trường hợp nào xuất hiện biến chứng tim mạch.

\section{KẾT LUÂN}

\subsection{Một số đặc điểm lâm sàng, cận lâm sàng UTTQ}

* Tuổi trung bình là 54,4; trẻ nhất là 43 tuổi, cao nhất là 69 tuổi, nhóm tuổi từ 50-60tuối chiếm tỷ lệ cao nhất $57,1 \%$.

* Tỷ lệ nam/nữ là 59/1

* Lý do vào viên chủ yếu là nuốt nghen $91,7 \%$, có $8,3 \%$ số bệnh nhân phát hiện tình cờ do khám kiểm tra sức khỏe

* Bệnh nhân ở giai đoạn T3, T4 lần lượt là $74,3 \%$ và $25,7 \%$. Bệnh nhẩn di căn hạch $71,4 \%$

\subsection{Kết quả đîều trị}

* Tý lệ đáp ứng hoàn toàn sau hóa xạ trị là 48,3\% Tỷ lệ đáp ứng một phần là 41,7\%. Tỷ lệ không đáp ứng là $10 \%$.

* Các thông số về liều tối ưu tại PTV kỹ thuật VMAT đều cho thấy bao phủ (V95\%) tốt hơn, quá liều (V110\%) ít hơn so với kỹ thuật 3D-CRT, liều chịu tại các cơ quan lành như tuỷ sống, phổi, tim khi sử dụng kỹ thuật VMAT đều thấp hơn kỹ thuật 3D-CRT

* Tác dụng phụ trên huyết học, sinh hóa máu ít gặp và không ảnh hưởng điều trị: hạ bạch cầu độ $1(10 \%)$; hạ tiểu cầu độ $1(1,7 \%)$, không có tác dụng phụ trên gan và thận

* Tác dụng phụ do xạ trị gặp chủ yếu là độ 1 : viêm thực quản độ $1(18,3 \%)$, viêm da độ 1 (41,7\%). Có 2 bệnh nhân viêm phổi độ 1 do xạ trị và đều xạ bằng kỹ thuật 3D-CRT.

\section{TÀI LIỆU THAM KHẢO}

1. Bray F, Ferlay J, Soerjomataram I, Siegel RL, Torre LA, Jemal A. Global cancerstatistics 2018: GLOBOCAN estimates of in cidenceand mortalityworldwidefor 36 cancers in 185 countries. CA Cancer J Clin. 2018;68(6):394-424. doi: 10.3322/caac. 21492

2. Nguyễn Chấn Hùng, Nguyễn Bá Đứ̛́c (2003). Kết quả bước đầu nghiên cứu dịch tế học mô tả môt số bênh ung thư taii 6 vùng đia lý Viêt Nam giai đoạn 2001-2003. Tạp Chí Học TPHCM. 13(5):23-64.

3. HànThị Thanh Bình (2004). Nhận xét đặc điểm lâm sàng, mô bệnh học và kết quả điều trị ung thư biểu mô thực quản tại bệnh viện K giai đoạn 1998 - 2004.Luânn văn Bác sỹ nội trú, Đại học Y Hà Nội

4. Carcinoma of the Esophagus. Accessed September 21, 2020. https://www. cambridge.org/ core/books/carcinoma-of-the 
esophagus/841ACDC360FA07FD66C139B2C18E734A

5. J S, Jjb van $L$, Mccm $H$, et al. Neoadjuvant chemoradiotherapy plus surgery versus surgery alone for oesophageal or junctional cancer (CROSS): long-term results of a randomised controlled trial. The Lancet. Oncology. doi:10.1016/S1470-2045(15)00040-6

6. Stahl M, Stuschke $M$, Lehmann $N$, et al. Chemoradiation withandwithoutsurgery in patientswithlocallyadvancedsquamouscellcarcinom a of the esophagus. J Clin Oncol Off J Am Soc Clin Oncol. 2005;23(10):2310-2317. doi:10.1200/ JCO.2005.00.034

7. Nguyễn Đức Lợi (2015). Đánh giá hiệu quả phác đồ hóa xạ đồng thời và một số yếu tố tiên lượng ung thư biểu mô thực guản giai đoạn III IV tại bệnh viện K. Luận án tiên sỹ y học, Đ̇ại học Y Hà Nội.

8. Tepper J, Krasna MJ, Niedzwiecki D, etal. Phase III Trial of Trimodality Therapy With Cisplatin, Fluorouracil, Radiotherapy, and Surgery Compared With Surgery Alone for Esophageal Cancer: CALGB 9781. J Clin Oncol Off J Am Soc Clin Oncol. 2008;26(7):1086-1092. doi:10.1200/ JCO.2007.12.9593

9. De Vita F, Di Martino N, Orditura M, etal. Preoperative Chemoradiotherapy for Squamous Cell Carcinoma and Adenocarcinoma of the Esophagus: A Phase II Study. Chest. 2002; 122(4):1302-1308. doi:10.1378/ chest.122.4.1302

\title{
ĐÁNH GIÁ KẾT QUẢ PHẪU THUÂT KẾT HỢP XƯƠ'NG NẸP VÍT ĐIỀU TRI GÃY KÍN LIÊN LÔI CẦU XƯO'NG CÁNH TAY Ở NGƯỜI TRƯở'NG THÀNH TẠI BÊ̂NH VIỆN HŨ̃U NGHI VIỆT ĐỨC
}

\author{
Đặng Hoàng $\mathrm{Nam}^{1}$, Nguyễn Xuân Thùy ${ }^{2,3}$, Trần Hoàng Tùng ${ }^{2}$
}

\section{TÓM TẮT}

Đặt vấn đề: Nghiên cứu đánh giá kết quả phẫu thuật kết hợp xương nẹp vít điều trị gãy kín liên lồi câu xương cánh tay ở người trưởng thành tại Bệnh viện Hữu nghị Việt Đức. Đối tượng và phương pháp nghiên cứu: Nghiên cứu hồi cứu và tiến cứu không đối chứng trên 46 bênh nhân được phầu thuâat kết hợp xương nẹp vít điều trị gãy kín liên lồi cầu xương cánh tay từ tháng 1/2019 đến tháng 3/2021. Kết quả: Đa số bệnh nhân ở độ tuổi từ 31 đến 60 tuổi $(47,8 \%)$, tai nan giao thông là nguyên nhân dẫn đến chấn thương chiếm tỷ lệ cao nhất $(54,4 \%)$ và tổn thương chủ yếu là loại C2 (63\%) theo phân loại tiêu chuẩn AO. Kết quả chung theo thang điêm của Morrey tốt và rất tốt chiếm tỷ lê cao $83,8 \%$, trung bình là $13,5 \%$, xấu là 2,7\%. Điểm Morrey trung bình đạt 83,4 \pm 11,2 điểm. Kết luận: Gãy kín liên lồi cầu xương cánh tay ở người trưởng thành loại $C$ theo phân loại của $\mathrm{AO}$ là kiếu gãy xương phạm khớp phức tạp. Phẩu thuật kết hợp xương nêp vít nhắm năn chỉnh phục hồi về giải phẩu, cố định ổ gãy vững chắc, tao điêu kiện để tập phục hồi chức năng sớm sau phấu thuật.

Tư khóa: Gãy kín liên lồi cầu xương cánh tay.

\section{SUMMARY \\ ASSESSMENT OUTCOMES OF INTERNAL OSTEOSYNTHESIS TREATMENT OF CLOSED DISTAL HUMERUS FRACTURE IN ADULT}

\footnotetext{
${ }^{1}$ Bênh viên Đa khoa tỉnh Thanh Hóa

${ }^{2}$ Bệnh viện Hữu nghi Việt Đức

${ }^{3}$ Trường Đại học Y Hà Nội

Chịu trách nhiệm chính: Đặng Hoàng Nam

Email: danghoangnamhmu@gmail.com

Ngày nhận bài: 28.7.2021

Ngày phản biện khoa học: 27.9.2021

Ngày duyệt bài: 1.10.2021
}

\section{AT VIET DUC HOSPITAL}

Introduction: Evaluate the result of internal osteosynthesis treatment of closed distal humerus fracture in adult at Viet Duc hospital. Method: A retrospective and prospective study without control on 46 patients who underwent internal osteosynthesis treatment of closed distal humerus fracturefrom $1 / 2019$ to 3/2021. Result: The majority of patients were between the ages of 31 and 60 years old $(47.8 \%)$, traffic accidents were the leading cause of injuries (54.4\%) and AO type C2 fractures were mainly on $63 \%$ cases. The overall outcome according to Broberg and Morrey scale, good and excellent accounted for a high rate of $83.8 \%$, fair was $13.5 \%$, and poor was $2.7 \%$. The average Morrey score was $83,4 \pm 11,2$. Conclusion: AO type $\mathrm{C}$ closed humerus fracture in adults is complex intercondylar fracture. The internal osteosynthesis treatment correct anatomical reduction, rigid fixation of fracture in order to improve early rehabilitation after surgery.

Keywords: Close distal humerus fracture

\section{I. ĐĂT VẤN ĐỀ}

Gãy đâu xa xương cánh tay có nhiều dạng, thường gặp các loại gãy trên lồi cầu, gãy lồi cầu ngoài và gãy liên lồi cầu. Trong đó gãy trên lồi cầu là loại gãy phổ biến nhất ở trẻ em. Ngược lại ở người lớn gãy trên lồi cầu là hiếm gặp (2-4\%) [1] gặp chủ yếu loại gãy liên lồi cầu.

Gãy liên lồi cầu xương cánh tay ở người trưởng thành là loại gãy xương phạm khớp phức tạp, đã được Desault mô tả lần đầu tiên từ năm 1881 [2]. Là loại gãy gây khó khăn nhất cho việc chỉ định điêuu trị, tùy thuộc vào bản chất thương tổn mà có thể điều trị bảo tồn, phẫu thuật kết hợp xương, hoặc thay khớp khuỷu. 